\title{
Tensões entre o não saber, o saber e o fazer no canto cênico
}

\author{
CHAVES, Marcos ${ }^{1}$
}

Resumo:

1.

O presente artigo dialoga sobre a tensão entre o saber e o fazer, a partir do "não saber", um olhar sobre barreiras encontradas/demonstradas pelos atores na prática do canto em encenações teatrais. Cruzamentos que passam pela educação em nossa cultura, que é visual, observando pontuações de Silvia Davini. Na comunicação, uma visão sobre o processo de criação de espetáculos que compunham a trilogia As Três Batidas de Molière, do grupo Farsa, de Porto Alegre-RS.

Palavras-chave:

Musicalidade no Teatro; Canto Cênico; Processo de Criação.

Marcos Machado Chaves é doutorando em Teatro pela Universidade do Estado de Santa Catarina e professor efetivo do curso de Artes Cênicas, da Universidade Federal da Grande Dourados. E-mail: marcoschaves12@gmail.com

\section{Abstract:}

This paper discusses about the tension between "knowing" and "doing", from the "not knowing", considering the barriers found and shown by some actors according to their theatrical performances during the practice of singing. There are some crossings that pass through education in our culture, that is mainly visual, as outlined by Silvia Davini. In this study we intended to analyze the process of creating plays that made up the trilogy The Three Molière Beats, of the Farsa group, from Porto Alegre-RS.

Keywords:

Musicality in Drama; Theatrical Singing; Creating Process. 
Inicio um diálogo a respeito da tensão entre o saber e o fazer, observando um ponto anterior: o não saber. Essas inquietações, que perpassam a área do conhecimento da psicologia, são potencializadas no fazer teatral, porque o ator sempre tem de atualizar ações em status de "(a/re)presenta-ação", de jogar com o efêmero.

Falo do campo da musicalidade cênica, que é um leque imenso. Acredito estarmos em um momento diferenciado no Brasil (percepção otimista), a respeito de pesquisas que tratam da sonoridade/musicalidade no teatro, visto que surgiram nos últimos anos - nos programas de pós-graduação em artes cênicas - mais estudos focados nesta área. Todavia, faz-se necessário, ainda, ressaltar algumas das diversas camadas do citado campo.

Música no teatro não é só música no teatro. Está conectada ao compositor musical, ao arranjo, às harmonias, ritmos, contrapontos e melodias, porém esse é um dos topos do iceberg da musicalidade cênica. Existem obras teatrais extremamente musicais sem a inserção de músicas. Tal aspecto aborda a percepção auditiva; aguça, nos artistas e espectadores, as sensações do ouvir. Está vinculado a uma filosofia musical conectada à escuta, ao som.

\footnotetext{
O que se visa propriamente ao ouvir o som como sinal não é o próprio som, mas aquilo que através dele é designado. $O$ ato de ouvir não para portanto no som, mas após ouvi-lo, deixa a escuta para ativar aquelas funções que logo se propendem para agarrar o objeto que é anunciado no som (PIANA, 2001, p. 85).
}

O tema saber e fazer é interessante no viés musical da cena. De um lado, temos o saber musical implícito ligado à cultura - a voz dos atores é um jogo de tonalidades, ritmos e acentos; o "sotaque" ou modulação vocal aplicado em um personagem/ tipo é um exemplo de característica musical que o ator trabalha organicamente com o intuitivo, com um saber inconsciente. De outro lado, observei em muitos atores com quem tive a oportunidade de trabalhar uma espécie de não saber envolto em uma série de preceitos quando tratamos de música cênica, principalmente quando, em um espetáculo teatral, os atores necessitam desempenhar o canto, o que gera um bloqueio.

Em meu processo de formação teatral (...) percebi o quanto as aulas de música deixavam inibidos grande parte dos estudantes. Eu, que vinha de uma formação musical anterior, habituada a me expressar musicalmente, fiquei inicialmente atônita ao ver pessoas normalmente tão seguras quase entrando em pânico por terem de repetir pequenos trechos melódicos ou rítmicos. A imagem de 
uma linda aspirante a atriz, que, tremendo e quase chorando, cantou com uma voz sumida, sem afinação nenhuma, nunca me saiu da retina (DIAS, 2009, p. 37).

Compartilho com os leitores o processo de criação de espetáculo teatral onde pude experienciar tensões dos atores com o canto cênico, em montagem de duas peças de Molière pelo grupo Farsa, de Porto Alegre-RS, ambas com direção de Gilberto Fonseca $^{2}$. O Avarento ${ }^{3}$ (2009) e Tartufo ${ }^{4}$ (2011) integraram a trilogia do grupo gaúcho intitulada As Três Batidas de Molière 5 , com a concepção de trabalhar o canto cênico nas obras.

As impressões que tenho a respeito da montagem destas peças perpassam diversos desdobramentos, pois assumi a criação/composição da trilha sonora, preparação vocal dos atores e direção musical do espetáculo, além de ter atuado. O espetáculo teatral $O$ Avarento foi o primeiro trabalho no qual eu pude notar uma real necessidade dos atores em relação a conhecimentos teóricos musicais.

Ao partir do trabalho com o canto cênico, iniciamos estudos e proposições do canto coral para aguçar a percepção sensível da escuta por meio de diferentes linhas melódicas. Nas primeiras reuniões, os artistas acabaram se manifestando sobre o que acreditavam poder acrescentar ou dificultar um processo. Um comentário dentro e fora deste espetáculo: percebo ser recorrente (em muitos trabalhos, peças, cursos, oficinas, as quais pude ministrar/participar/observar em outros grupos e cidades) o costume de assumir o não saber quando se trata do ator cantar em cena. Interessante ao pensar sobre tensões entre o saber e fazer, um olhar que parte do não saber para adquirir conhecimento visando à prática.

Podemos encontrar em educadores musicais, como o canadense Murray Schafer, a necessidade da "limpeza" no ouvir, escutar os sons do ambiente. Aguçar a escuta como matriz criativa e de relação para a cena foi o foco enfatizado com os atores de $O$ Avarento e Tartufo, assim como a necessidade da percepção auditiva para, depois, chegar à voz falada e cantada.

Em linhas gerais, existe uma ideia, no senso comum, de que o trabalho vocal dos atores no Brasil é deficiente. Esta deficiência se dá por diversos fatores. Entendo como relevante motivo as poucas horas-aula destinadas às disciplinas direcionadas à vocalidade, sonoridade e musicalidade nos cursos de formação de atores, ou mesmo a falta de trabalhos desta natureza. Os atores brasileiros trabalham/exercitam pouco suas vozes, apesar de compreenderem a importância da voz na cena. Silvia Davini, professora da Universidade de Brasília, pontua que, no final do século $\mathrm{XX}$, estudantes e professores declaravam a preparação vocal como "uma instância primor-
2.

Mestre em Artes

Cênicas pela

Universidade Federal do Rio Grande do Sul,

fundador do grupo

Farsa (Porto Alegre-RS),

estando à frente da

trupe de 2003 a 2012.

3.

Montagem contemplada com o Prêmio Funarte de Teatro Myriam Muniz (2008) - Região Sul.

4.

Espetáculo financiado pelo Fundo Municipal de Apoio à Produção Artística e Cultural de Porto Alegre (FUMPROARTE), Prefeitura Municipal de Porto Alegre, através do edital 01/2010.

5

A trilogia previu sua conclusão com O Doente Imaginário ou As Preciosas Ridículas; a montagem encontra-se em projetos de captação. 
dial e inevitável na formação dos atores, mas a quantidade e carga horária das matérias vinculadas à voz na encenação nos planos de estudo dos cursos de artes cênicas eram muito limitadas"6 (DAVINI, 2007, p. 13, tradução livre).

Este é um retrato do que acredito ser a principal questão: a ausência da educação musical nas escolas de ensino básico (cenário que tende a ser modificado lentamente, pois estamos vivenciando a implantação do conhecimento de música no ensino básico segundo a lei de diretrizes e bases). Tal retrato está relacionado ao fato de vivermos em uma sociedade culturalmente visual: os atores possuem interesse no trabalho de voz, mas, quando chega o momento da preparação, surge o que Davini nomeou de "ansiedade vocal".

\footnotetext{
Não é fácil para os estudantes de teatro perceber e localizar suas vozes ou compreender seus comportamentos. Se para uma cultura orientada visualmente o que não é visível não existe, poderíamos inferir que, pertencendo à esfera do acústico, a voz e a palavra proferida teriam sua presença enfraquecida na performance ${ }^{\supset}$ (DAVINI, 2007, p. 15, tradução livre).
}

Silvia Davini pontua a dificuldade que os atores possuem quando necessitam aguçar, mostrar, demonstrar musicalidades em cena, principalmente com a voz. É importante ressaltar que parto do pressuposto de que o ator, ao executar o canto, é um ator que canta. É um ator que não necessariamente precisa ter domínio técnico, e sim a busca de um registro confortável para a execução.

O não saber manifestado pelo ator ao se deparar com a designação de cantar em cena apresenta-se como um impeditivo. Na música para teatro, imagino que ele seja um empecilho um pouco maior do que outros problemas com o próprio cantar. O bloqueio imposto pelo ator dificulta o acesso do preparador vocal: é como o medo de absorver algo novo que o exponha a lidar com o risco.

Há duas formas de não saber: uma conectada à ignorância, que é o "não saber que não sabe", e o "não saber" consciente. Em exercício hipotético, se uma pessoa afastada de centros urbanos não conhece o telefone celular, como afirmar que ela não sabe utilizar o aparelho? Parece evidente, pois ela o desconhece. Assim que for apresentada tal tecnologia à pessoa, a mesma terá duas opções: procurar saber utilizá-lo ou não se interessar por aprender. A partir deste momento o fator desconhecimento cai, pois o "não saber" é uma opção ou condição. Um exemplo parecido está na popularização da internet: façamos um exercício de memória, pois este cenário mudou
6.

No original:

"Estudiantes y profesores declaraban en forma unánime que la preparación vocal es una instancia primordial e ineludible en la formación de actores. Sin embargo, la cantidad y la carga horaria de las materias vinculadas a la voz en performance en los planes de estudio de los cursos de artes escénicas eran muy limitadas"

(DAVINI, 2007, p. 13).

7 .

No original: "No resultaba fácil para los estudiantes de teatro percibir y localizar sus voces o comprender sus comportamientos. Si para una cultura orientada visualmente lo que no es visible no existe, podríamos inferir que, perteneciendo a la esfera de lo acústico, la voz y palabra proferida habrían visto debilitada su presencia en performance" (DAVINI, 2007, p. 15). 
completamente nas últimas duas décadas. Para as pessoas consideradas jovens, o uso/aprendizado de navegação na rede virtual parecia orgânico, em contraponto com pessoas com trajetória de vida mais longa, que mostravam dificuldades em apreender a nova tecnologia. Quem não tem um parente ou conhecido que até hoje recusa tal recurso? Aí está presente o "não saber" enquanto escolha.

Para o ator, lidar com o não saber e estar disposto a apreender visando a executar a performance cênica é algo positivo, assim como ocorre em todas as áreas artísticas. Já o trabalho de música voltado para o teatro, quando visto como uma barreira pelo artista da cena, acaba por amplificar o não saber.

No processo de criação de O Avarento, em um elenco de oito pessoas (contando comigo), duas tinham prática com canto. Alguns colegas mostravam facilidades e dois artistas manifestavam com veemência "eu não sei e não consigo cantar". JeanJacques Lemêtre, compositor do Théâtre du Soleil e parceiro criativo da diretora Ariane Mnouchkine, ao ministrar um curso na cidade de Porto Alegre (em dezembro de 2012), citou aos alunos-ouvintes que as pessoas costumam dizer (sobre si) que não possuem ritmo ou que não sabem cantar. Lemêtre propôs uma reflexão mediante uma colocação interessante: as pessoas dizem que não têm ritmo, mas têm um coração que bate. Todos nós temos um ritmo interno. As pessoas que dizem não saber cantar, falam. Por meio da fala nós exercitamos variação de notas, intensidade, altura e duração. Não seria a fala um tipo de música?

Na primeira obra da trilogia de Molière do grupo Farsa, sabendo das dificuldades do grupo, dividi o elenco em naipes, como um grupo coral, e procurei trabalhar o não saber para que descobríssemos uma forma do saber. A prática de canto em grupo (coro) para a cena é positiva pelo sentido coletivo: você não expõe o ator cantando solo e valoriza o material de que dispõe.

Como eu estava fazendo a preparação, direção musical e, também, a criação das músicas, procurei descobrir as tonalidades com que o coletivo estava desempenhando exercícios vocais de forma orgânica. Houve um ator - que foi o mais enfático no não saber enquanto barreira - que, durante o processo, mostrou-se confiante na condução e nos colegas. Acabamos descobrindo uma cumplicidade de entrega no fazer para que construíssemos em cada apresentação uma nova música: isso era dado pelo olhar durante a execução do canto. Talvez isso tenha aparecido como um facilitador no processo, pois o criador das músicas cênicas também estava presente na atuação. Pôde ser criada, no entanto, uma relação de condução 
do canto cênico com todos os atores, levando a uma apropriação do material para execução. Em outras palavras, quem sabia um pouco mais sustentava/conduzia a prática do canto cênico em coro, colaborando com os colegas que, a princípio, mostravam-se inseguros.

A barreira do não saber acaba se transformando em uma forma do saber; daí a disponibilidade para se abrir ao saber e a essa linha tênue do fazer, do conseguir executar e fazê-lo sem ser um "robô", sem ser apenas "técnico". O ator consegue demonstrar o que sabe, o que praticou, dialogou, e que materiais sonoros pode compartilhar com os colegas.

Já em Tartufo, uma especificidade diferenciada: a inserção de uma banda na encenação, uma banda formada pelos atores. Enquanto diretor musical, dialoguei com o diretor de cena sobre a possibilidade de convidarmos músicos para compor a obra. Acordamos sobre chamar um músico, guitarrista, pois em minha concepção musical surgiu a necessidade de solos deste instrumento. Os outros instrumentos deveriam ser assimilados pelo elenco, composto por dez pessoas, seis delas oriundas do elenco de O Avarento.

A inspiração para Tartufo estava em pessoas que se utilizam da fé para enganar o próximo, tema explorado por JeanBaptiste Poquelin no seu texto. Buscamos referências em organizações contemporâneas, os "tartufos" de hoje. Algo próximo ao personagem desempenhado por Steve Martin no filme Fé demais não cheira bem ${ }^{8}$. Esse foi um dos motes para utilizar a banda em cena.

O processo de aprendizado de um instrumento musical é lento, ou melhor, gradativo. Como tempo é algo precioso em montagem de espetáculo teatral, procuramos observar facilidades. Atores com bom desempenho rítmico nos jogos e exercícios na preparação musical passaram a se descobrir bateristas. Formou-se, então, um trio com guitarra (músico convidado), teclado (executado por mim) e bateria (dois atores revezavam músicas).

Ressalto as designações das funções: os atores que tocam instrumentos musicais em obra de teatro passam a ser atoresinstrumentistas (ou atores-músicos) - não importa se pouco dominam a ferramenta, assim como o músico inserido em peça teatral torna-se músico-ator. Atores que cantam na cena são atores-cantores. Acho importante conceituar essas denominações, porque carregam sentidos e significados que o artista deve assumir em cena. Os atores-cantores de Tartufo tiveram um desafio a mais: cantar em cena com microfones.

Das tensões entre não saber, saber e fazer no canto cênico, o cantar com o uso de microfones potencializa os conflitos. O 
microfone evidencia uma nota semitonada, além de causar estranhamento a quem não está acostumado a ouvir sua própria voz amplificada. Aproximando a concepção da segunda obra da trilogia, microfones e instrumentos musicais foram plugados nos aparatos e caixas de som.

Para que os atores experienciassem o uso do microfone em contato com os espectadores e lidassem com propriedades do saber e fazer antes da estreia do espetáculo, propus um evento-exercício musical semelhante a atuais programas de auditório (tevê aberta e/ou fechada), no qual o intérprete cantava sozinho no palco (apenas a pessoa com o microfone) e jurados analisavam a performance. Surgiu o Tartufo Idol?.

Na progressão para o evento mencionado, desenvolvi um cronograma de ensaios individuais para que os atores escolhessem suas músicas, treino e preparação visando à performance musical. Considero o resultado como positivo para os envolvidos e para o processo de montagem do espetáculo, naquela interação. Pequenas superações apareceram como experiências; por exemplo, uma atriz que assumia o não saber como bloqueio realmente mostrava dificuldades no percurso, mas conseguiu estar frente ao público e artistas convidados ${ }^{10}$ para jogar com o grupo, que assumiu o papel de júri. Quem a assistiu no evento certamente não observou bom desempenho em relação aos outros atores-cantores, porém a atriz e eu (enquanto diretor musical) sabíamos a evolução da artista em relação à sua própria musicalidade, vocalidade poética e percepção auditiva.

As trajetórias de O Avarento e Tartufo foram marcantes para o grupo Farsa e para os artistas envolvidos. O primeiro espetáculo teve três anos de percurso, o segundo rodou por um ano. No caminho, cidades e festivais pelo Brasil, e uma das características significativas ${ }^{11}$ citada por críticos e espectadores foi a música de cena com o canto executado ao vivo - com o coro explorado pelos atores.

No canto cênico, tensões permanecem presentes dentro de uma forma de saber (dialógica com o não saber) que é sempre reconfigurada, em toda apresentação, porque cada espaço diferente, cada reverberação diferenciada do espaço cênico acaba como uma informação lida, absorvida e recriada no fazer.
Realizado no Teatro de Arena (Porto Alegre-RS) em 24 de março de 2011. O experimento pode ser visualizado no youtube (TARTUFO IDOL, 2013).

10.

Mirna Spritzer - atriz e professora do Programa de Pós-Graduação em Artes Cênicas da Universidade Federal do Rio Grande do Sul; Nico Nicolaiewsky - músico, compositor e ator (dentre diversas obras, destaque para Tangos \& Tragédias, espetáculo criado em 1984 que segue em cartaz); e Protásio Jr. - músico e desenhista de som, trabalha no estúdio Submarino Amarelo em Porto Alegre-RS.

11.

O Avarento - indicado ao Prêmio Açorianos de Teatro 2009 por melhor trilha sonora (Porto Alegre-RS); premiado no $38^{\circ}$ Festival Nacional de Teatro (Ponta Grossa-PR). Tartufo - indicado ao Prêmio Açorianos de Teatro 2011 por melhor trilha sonora (Porto Alegre-RS); premiado no $39^{\circ}$ Festival Nacional de Teatro (Ponta Grossa-PR). 


\section{REFERÊNCIAS}

CHAVES, Marcos. A trilha sonora teatral em pauta: experiências de criadores de trilha sonora em Porto Alegre. Dissertação de Mestrado defendida no Programa de Pós-Graduação em Artes Cênicas, Instituto de Artes, Universidade Federal do Rio Grande do Sul. Porto Alegre-RS, [s.n], 2011.

DAVINI, Silvia. Cartografías de la voz em el teatro contemporaneo: el caso de Buenos Aires a fines del siglo XX. Bernal: Universidad Nacional de Quilmes, 2007.

DIAS, Ana. Ator, cena e musicalidade. In: CASTILHO, Jacyan (org). Música e musicalidade no espetáculo teatral. Revista Vox da Cena, Salvador, BA: Ano I nº 1, março de 2009.

IGLESIAS SIMÓN, Pablo. El diseñador de sonido: función y esquema de trabajo. Madrid, España: ADE-Teatro, no 101, JulioAgosto, 2004. pp. 199-215.

MED, Bohumil. Teoria da música. Brasília, DF: Musimed, 1996. PIANA, Giovani. A Filosofia da música. Bauru, SP: EDUSC, 2001. SCHAFER, R. Murray. O ouvido pensante. São Paulo: Fundação Editora da UNESP, 1991.

TARTUFO IDOL. Um exercício musical no processo de criação de um espetáculo teatral. Disponível em: http://www.youtube. com/watch?v=_M1rgvq19Oc Acesso em 20/06/2013. 